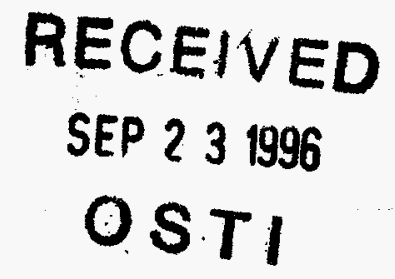

LS-90 (AWL)

H. J. Moe
V. R. Veluri

Apri1 1987

\title{
Shielding Estimates for the ANL Advanced Photon Source
}

\subsection{Introduction}

Shielding estimates for the Advanced Photon Source (APS) have been computed utilizing presently avallable design parameters. Calculations of the resulting radiation fields have been made for several considerations involving normal beam loss, as well as for certain postulated accidental beam losses. Whenever available, experimental data from existing accelerators and light sources have been used in lieu of theoretical estimates.

\subsection{Shielding Design Objective}

The Department of Energy's (DOE) basic occupational exposure limit is 5 rem per year (DOE 81). However, in applying the ALARA ("as low as reasonably achievable") philosophy, one must strive to maintain exposures below this limit. In particular, the DOE guidance in the same document states that the ALARA design objective for new facilities is to limit exposures to one-fifth of 5 rem per year ( $\sim 0.5 \mathrm{mrem} / \mathrm{h}$ for a $40-\mathrm{h}$ work week). An additional ALARA guideline proposed in 1984 (DOE 84) is that predicted exposures to individual members of the public should not exceed 25 mrem per year. These dose limiting objectives have been used as the basis for the shielding design estimates for the normal operations of the facility.

\subsection{Types of Radiation Considered}

Depending upon the positron energy and beam characteristics, a number of radiation products need to be considered. High-energy positrons or electrons produce electron-photon cascades or showers when deliberately or accidentally stopped in materials. These electromagnetic showers give rise to a spectrum of bremstrahlung photons with energies ranging up to the incident particle energy, in addition to releasing more electrons and positrons. This component of the radiation field is referred to as bremsstrahlung (BREM) 


\section{DISCLAIMER}

Portions of this document may be illegible in electronic image products. Images are produced from the best available original document. 


\section{DISCLAIMER}

This report was prepared as an account of work sponsored by an agency of the United States Government. Neither the United States Government nor any agency thereof, nor any of their employees, makes any warranty, express or implied, or assumes any legal liability or responsibility for the accuracy, completeness, or usefulness of any information, apparatus, product, or process disclosed, or represents that its use would not infringe privately owned rights. Reference herein to any specific commercial product, process, or service by trade name, trademark, manufacturer, or otherwise does not necessarily constitute or imply its endorsement, recommendation, or favoring by the United States Government or any agency thereof. The views and opinions of authors expressed herein do not necessarily state or reflect those of the United States Goverament or any agency thereof. 
radiation and can lead to photon radiation fields outside of the shield. The radiation originating in the shower is highly peaked in the forward direction of the positron beam. However, the transverse component is still significant and cannot be neglected. As the energy of the positron beam increases, three other component radiations need to be considered. The first of these components is the Giant Resonance Neutrons (GRN) produced by photonuclear interactions (threshold energy $\sim 7-20 \mathrm{MeV}$ ). This component has an average effective energy of about $2 \mathrm{MeV}$ and is emitted almost isotropically. As the positron energy moves above several hundred MeV, high-energy neutrons $(>100 \mathrm{MeV})$ and muons are also produced. Considering a maximum energy of $7.7 \mathrm{GeV}$, and an upper 1 imit of $0.3 \mathrm{~A}$ for the current, the muons are of minimal importance, since their production rate is still small and they are highly peaked in the forward direction (FAS 84). The high energy neutron component (HEN) is not isotropic, but in many shielding situations, only the neutron radiation field in the transverse direction is important. All these radiations have been considered under appropriate conditions to estimate the shielding requirements.

In addition to the above radiations which arise when positrons interact with matter, other photon radiation, referred to as synchrotron radiation, is produced when positrons are bent in magnetic fields. This radiation is generally in the $\mathrm{keV}$ region for the APS and is greatly attenuated by the vacuum chamber itself. The presence of shielding for the abovementioned radiation components assures that synchrotron radiation which escapes the vacuum chamber will also be adequately shielded by the tunnel.

\subsection{Radiation Attenuation Parameters}

Information on the attenuation of bremsstrahlung, giant resonance neutrons, and the high-energy component by various shielding materials was obtained from the 1iterature. For a given material, one discovers a spread in the quoted values for the attenuation lengths for a given type of radiation. A variety of references which discuss these attenuation lengths have been reviewed, such as ALS 73, BAT 67, BAT 70, DIN 77, FAS 84, NEL 68, SWA 79, SWA 85 , TES 79 and others. 
In all cases, we have attempted to use conservative values for the attenuation lengths in order to provide a margin of safety. The following table lists the attenuation lengths for various potential shielding materials examined in this study.

ATTENUATION LENGTHS

\begin{tabular}{|c|c|c|}
\hline Radiation Component & Shielding Material & $\begin{array}{l}\text { Attenuation } \\
\text { Length }\left(\mathrm{g} / \mathrm{cm}^{2}\right)\end{array}$ \\
\hline \multirow[t]{5}{*}{ Bremsstrahlung } & Lead & 25 \\
\hline & Concrete & 49 \\
\hline & Heavy Concrete & 50 \\
\hline & Iron & 37 \\
\hline & Sand (earth) & 70 \\
\hline \multirow[t]{6}{*}{ Giant Resonance Neutrons } & Concrete & 40 \\
\hline & Heavy Concrete & 45 \\
\hline & Dense Polyethylene & 6.3 \\
\hline & Sand (earth) & 33 \\
\hline & Iron (backed by $\mathrm{H}$ ) & 100 \\
\hline & Lead (backed by $\mathrm{H}$ ) & 161 \\
\hline \multirow[t]{3}{*}{ High Energy Neutrons } & Concrete & $65(\mathrm{E} \leqslant 100 \mathrm{MeV})$ \\
\hline & & $115(E \geqslant 100 \mathrm{MeV})$ \\
\hline & Dense Polyethylene * & $62(E \geqslant 100 \mathrm{MeV})$ \\
\hline
\end{tabular}

* Scaled from GRN data 


\subsection{Radiation Dose Equivalent Factors}

The unshielded radiation-dose equivalent factors used in the shielding computations have been adapted from Fasso, et al. (FAS 84), with their suggested modifications. These factors are:

$$
\begin{aligned}
& \text { Radiation Dose Equivalent } \\
& \text { Factor, } F_{H} \cdot\left(\frac{\mathrm{mrem} \cdot \mathrm{m}^{2}}{\mathrm{~J}}\right)
\end{aligned}
$$

Radiation Component

$\begin{array}{ll}\text { Bremsstrahlung } & 2.8^{*} \\ \text { Giant Resonance Neutrons } & 0.63 \\ \text { High Energy Neutrons } & 0.075\end{array}$

* Use $28 \frac{\text { mrem } \cdot \mathrm{m}^{2}}{\mathrm{~J}}$ for the completely unshielded bremsstrahlung component.

These factors refer to unshielded dose rates at $1 \mathrm{~m}$ in the transverse direction to the positron beam. As noted, in the absence of any shielding, the bremsstrahlung component will include a soft radiation component ( $\mathrm{e}^{-}$and $\mathrm{e}^{+}$), which is generally neglected since the above factors assume that sufficient shielding is present to assure attenuation of the particle component, $\sim 25 \mathrm{~cm}$ of concrete (DIN 77 ).

In the forward direction with respect to the positron beam ( 0 degrees), the value of $F_{H}$ for bremstrahlung is given by

$$
8.3 \mathrm{E}_{\mathrm{O}} \frac{\mathrm{mrem} \cdot \mathrm{m}^{2}}{\mathrm{~J}}(\mathrm{FAS} 84, \text { SWA } 79) \text {, }
$$

in which $E_{0}$ is the initial positron energy in MeV. In general, the same values given in the table above are used for the GRN and HEN components in the forward direction. 


\subsection{Bulk Shielding Calculations}

The following expression was used to compute the bulk shielding requirements for point losses in the various components of the APS system. The total dose equivalent rate $\dot{H}$ is given by

$$
\dot{H}=\sum_{l} \frac{\mathrm{F}_{\mathrm{H}_{\mathrm{l}}}{ }^{\mathrm{W}}}{\mathrm{r}^{2}} \mathrm{e}^{-\mathrm{d} / \lambda_{\mathrm{l}}} \text {, }
$$

in which $\dot{H}$ has units of mrem/s or $\mathrm{mrem} / \mathrm{h}, \mathrm{F}_{\mathrm{H}_{l}}$ is the appropriate factor from the table above, for the $i^{\text {th }}$ radiation component, $r$ is the source to dose point distance in $\mathrm{m}, \mathrm{d}$ is the shield thickness in $\mathrm{g} / \mathrm{cm}^{2}, \lambda_{\mathrm{l}}$ is the attenuation length for the $t^{\text {th }}$ radiation component, in $\mathrm{g} / \mathrm{cm}^{2}$, and $W$ is the energy loss rate in $\mathrm{J} / \mathrm{s}$ or $\mathrm{J} / \mathrm{h}$.

The shielding strategy employed was to use sufficient concrete as a bulk shield to provide reasonable global shielding of the various accelerator components for the distributed losses in the system. The shielding was then supplemented by localized shielding employing lead and/or dense polyethylene to reduce the radiation field from high loss points in order to meet the guidelines.

\subsection{Shielding for Linacs and Positron Converter}

\subsection{Linac Parameters}

The physical parameters used for the electron linac, the positron converter, and the positron linac are as follows:

$E=200 \mathrm{MeV}$ for $e^{-}$for positron conversion, $450 \mathrm{MeV}$ for $\mathrm{e}^{+}$

$I=3 \mathrm{~A}$ at $16.5-\mathrm{ns}$ pulse width, $8 \mathrm{~Hz}$ for $\mathrm{e}^{-}, 10 \mathrm{~mA}$ for $\mathrm{e}^{+}$

Conversion efficiency in tungsten -300 to 1

Linac tunnel - 9' by $9^{\prime}$

Beam height - 5' above floor level

Distance to dose point $-4 \mathrm{~m}$ 


\subsection{Estimated Beam Losses in Linac System}

For the components of the Linac system, the shielding computations were primarily based upon point losses in the various sections of the system. Since the beam characteristics of the ANL system are somewhat similar to the CERN-LEP linac system, estimates of fractional beam losses in the various components of the system were taken from Fasso, et al. (FAS 84). These are:

Estimated Linac Systen Losses

\begin{tabular}{|c|c|c|c|c|c|}
\hline Component & $\bar{I}(\mu \mathrm{A})$ & Loss $(\%)$ & $\begin{array}{c}\text { Average } \mathrm{E} \\
(\mathrm{MeV})\end{array}$ & $\begin{array}{c}\text { Average } \\
\text { et }\end{array}$ & $\begin{array}{c}\text { Power (Watts) } \\
\text { e- }\end{array}$ \\
\hline \multirow[t]{2}{*}{ Gun Output } & 1.0 & & & & \\
\hline & & 55 & 5 & & 2.75 \\
\hline \multirow[t]{2}{*}{ Buncher Output } & 0.45 & & & & \\
\hline & & 10 & 100 & & 4.5 \\
\hline \multirow[t]{2}{*}{$\begin{array}{l}\text { First Linac } \\
\text { Output }\end{array}$} & 0.405 & & & & \\
\hline & & 100 & 200 & & 81 \\
\hline \multirow[t]{2}{*}{$\begin{array}{l}\text { Second Linac } \\
\text { Output }\end{array}$} & 1.35 & & & & \\
\hline & & 40 & 225 & 0.12 & \\
\hline Resolved Output & $8.1 \times$ & & & & \\
\hline
\end{tabular}

\subsection{Shielding Estimates}

\subsubsection{Electron Linac}

The shielding for the Electron Linac was based upon the estimated power losses in the above table. The required shielding in any section was determined by the highest value of power lost. For the Electron Linac, the largest power loss is $4.5 \mathrm{~W}$. The computed dose rates for a concrete shielding of $2 \mathrm{~m}$ and a total distance of $4 \mathrm{~m}$ are: 


$$
\begin{aligned}
& \dot{\mathrm{H}}_{\mathrm{BREM}}=\frac{2.8(4.5) 3.6 \times 10^{3}}{(4)} \mathrm{e}^{-\frac{200(2.35)}{49}}=0.19 \mathrm{mrem} / \mathrm{h} \\
& \dot{\mathrm{H}}_{\mathrm{GRN}}=\frac{0.63(4.5) 3.6 \times 10^{3}}{(4)^{2}} \mathrm{e}^{-\frac{200(2.35)}{40}}=0.05 \mathrm{mrem} / \mathrm{h} \\
& \dot{\mathrm{H}}_{\mathrm{HEN}}=\frac{0.075(4.5) 3.6 \times 10^{3}}{(4)^{2}} \mathrm{e}^{\frac{-200(2.35)}{65}}=0.055 \mathrm{mrem} / \mathrm{h}
\end{aligned}
$$

The total dose rate is $0.25 \mathrm{mrem} / \mathrm{h}$, which is within the design guidelines.

\subsubsection{Positron Converter}

The power loss in the positron converter is significantly higher ( $81 \mathrm{~W})$ than that in the first linac $(4.5 \mathrm{~W})$. Referring to the results for the first linac, the dominant radiation component penetrating the shield is the bremsstrahlung. With $0.3 \mathrm{~m}$ of steel (iron), followed by $1.7 \mathrm{~m}$ of concrete, the computed dose rates at $4 \mathrm{~m}$ are:

$$
\begin{aligned}
& \dot{\mathrm{H}}_{\mathrm{BREM}}=\frac{2.8(81) 3.6 \times 10^{3}}{(4)^{2}} \mathrm{e}^{-\frac{30(7.8)}{37}} \mathrm{e}^{-\frac{170(2.35)}{49}}=0.026 \mathrm{mrem} / \mathrm{h} \\
& \dot{\mathrm{H}}_{\mathrm{GRN}}=\frac{0.63(81) 3.6 \times 10^{3}}{(4)^{2}} \mathrm{e}^{-\frac{30(7.8)}{100}} \mathrm{e}^{-\frac{170(2.35)}{40}}=0.051 \mathrm{mrem} / \mathrm{h} \\
& \dot{\mathrm{H}}_{\mathrm{HEN}}=\frac{0.075(81) 3.6 \times 10^{3}}{(4)^{2}} \mathrm{e}^{-\frac{200(2.35)}{65}}=0.99 \mathrm{mrem} / \mathrm{h}
\end{aligned}
$$

In the expression for the HEN component, the results of Alsmiller and Barish (ALS 73) were used. They indicate that the attenuation of the high-energy component by a thickness of iron, followed by a certain thickness of hydrogenous media, is approximately equal to the attenuation afforded by a total thickness of hydrogenous material equal to the thickness of the iron plus the hydrogenous medium. In this case, the total dose rate, $1.07 \mathrm{mrem} / \mathrm{h}$, exceeds the design goal. However, since the operational time for injection will be less than $20 \%$ of the total operation time, the average dose rate will be $<0.21 \mathrm{mrem} / \mathrm{h}$. With the addition of localized shielding, dense polyethylene and/or lead, around the converter target, the total dose rate outside of the Linac tunnel can be reduced to within the guideline $(<0.5 \mathrm{mrem} / \mathrm{h})$. 


\subsubsection{Positron Linac}

In the positron Linac, the power losses are down significantly due to the reduced positron current and the suggested $2 \mathrm{~m}$ of concrete shielding is adequate. This shielding also stops the scattered radiation in the forward direction which results from electrons and photons produced by interactions in the tungsten converter target.

\subsection{Shfelding for the Booster Synchrotron}

\subsection{Shielding for Injection from Linac to Synchrotron}

For the booster synchrotron, we assume a positron energy of $450 \mathrm{MeV}$, with a loss rate of $50 \%$ at the injection point. For injection of $5 \times 10^{9}$ $e^{t} / s$, the loss rate is

$$
5 \times 10^{9}(.5)(450)\left(1.6 \times 10^{-13}\right)\left(3.6 \times 10^{3}\right)=648 \mathrm{~J} / \mathrm{h} .
$$

For an $0.8 \mathrm{~m}$ concrete shield and a distance of closest approach of $3 \mathrm{~m}$, the estimated dose rates are:

$$
\begin{aligned}
& \dot{\mathrm{H}}_{\mathrm{BREM}}: 4.35 \mathrm{mrem} / \mathrm{h} \\
& \dot{\mathrm{H}}_{\mathrm{GRN}}: 0.41 \mathrm{mrem} / \mathrm{h} \\
& \dot{\mathrm{H}}_{\mathrm{HEN}}: 0.30 \mathrm{mrem} / \mathrm{h}
\end{aligned}
$$

The total dose rate of $5.06 \mathrm{mrem} / \mathrm{h}$ is above the guidelines. With the addition of $10 \mathrm{~cm}$ of lead shielding at high loss points, the bremsstrahlung dose rate will be reduced to $0.04 \mathrm{mrem} / \mathrm{h}$. Assuming a $20 \%$ operational time for injection results in a remaining average dose rate of about $0.15 \mathrm{mrem} / \mathrm{h}$. As an alternative, for the addition of $10 \mathrm{~cm}$ of dense polyethylene, in addition to the lead, at high loss points, the total dose rate will be reduced to about $0.3 \mathrm{mrem} / \mathrm{h}$.

Except for the injection and extraction areas, the shielding for the synchrotron consists of $0.3 \mathrm{~m}$ of concrete on the sides and roof of the tunnel, supplemented by earth berms to achieve an equivalent shield of $0.8 \mathrm{~m}$ concrete. 


\subsection{Accidental Loss of Beam in Booster}

For this case, consider a point loss of the positron beam $\left(5 \times 10^{9}\right.$ $\mathrm{e}^{+}$at $\left.7 \mathrm{GeV}\right)$ along the circumference of the synchrotron ring $(367 \mathrm{~m})$. Assuming the distance of closest approach is $3.5-\mathrm{m}$ and $0.8-\mathrm{m}$ concreteequivalent shielding, the dose per occurrence would be:

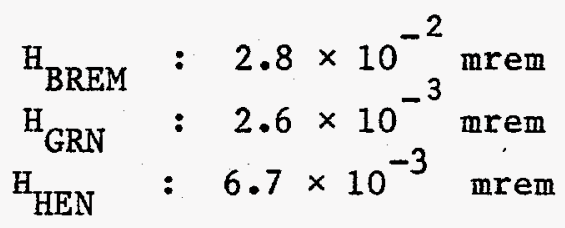

For 1000 fills of the storage ring per year, considering one occurrence for each 500 pulses in the synchrotron during filling, the number of occurrences per year would be about

$$
5300\left(\frac{\sim 6.62 \times 10^{12} \mathrm{e}^{+} / \mathrm{fill} \cdot 1000 \mathrm{fills}}{5 \times 10^{9} \mathrm{e}^{+} / \mathrm{pulse}(0.5) 500 \frac{\text { pulses }}{\text { occ. }}}\right) .
$$

This would result in a total dose of about 200 mrem from all occurrences, and this dose would be expected to be somewhat distributed around the synchrotron ring.

\subsection{Shielding for Extraction from Synchrotron to Storage Ring}

For the extraction of the beam from the synchrotron into the storage ring, a point loss of $50 \%$ was assumed. For a beam of $5 \times 10^{9} \mathrm{e}^{+} / \mathrm{s}$ at $7 \mathrm{GeV}$, the loss rate is $1.008 \times 10^{4} \mathrm{~J} / \mathrm{h}$. The computed dose rates at a distance of $4 \mathrm{~m}$ with $0.8 \mathrm{~m}$ of concrete shielding are:

$$
\begin{aligned}
& \dot{\mathrm{H}}_{\mathrm{BREM}}: 38 \mathrm{mrem} / \mathrm{h} \\
& \dot{\mathrm{H}}_{\text {GRN }}: 3.6 \mathrm{mrem} / \mathrm{h} \\
& \dot{\mathrm{H}}_{\mathrm{HEN}}: 9.2 \mathrm{mrem} / \mathrm{h}
\end{aligned}
$$

The total dose rate is $50.8 \mathrm{mrem} / \mathrm{h}$. Addition of $20 \mathrm{~cm}$ of lead at high-loss points would reduce the bremstrahlung dose rate to $0.38 \mathrm{mrem} / \mathrm{h}$. Adding $25 \mathrm{~cm}$ of dense polyethylene at these same high loss points would reduce the GRN and HEN dose rates to $6.5 \times 10^{-2}$ and $2.28 \mathrm{mrem} / \mathrm{h}$, respectively. For an assumed 
extraction time of about $20 \%$ operational time, the average total dose rate will be reduced to the design goal. The additional lead and dense polyethylene will be required only at the high-loss points of the extraction system, such as at septum, bump, or other bending and focusing magnets.

\subsection{Storage Ring Shielding}

\subsection{Parameters}

Shielding calculations for the storage ring were based upon the assumption that a maximum beam of $6.62 \times 10^{12} \mathrm{e}^{+}$at $7 \mathrm{GeV}$ must be shielded. Minimum tunnel dimensions of $9^{\prime}$ by $9^{\prime}$ were used, and a concrete thickness of $0.8 \mathrm{~m}$ on both sides and $1 \mathrm{~m}$ on the top of the tunnel were assumed. The circumference of the positron orbit was taken as $1060 \mathrm{~m}$. The distance of closest approach was taken as $2 \mathrm{~m}$. The shielding on the inside of the tunnel consists of a circular annulus ( $0.8 \mathrm{~m}$ concrete), concentric with the orbit. The shielding on the outside of the tunnel (experimental area side) is in the form of a ratchet wheel, or saw-tooth, pattern in order to increase the space available for photon beam line equipment.

\subsection{Continuous Loss During Beam Decay}

As the positron beam moves around the storage ring, there will be a continuous loss of positrons from the beam due to several different factors. Collisions of positrons with gas molecules, interactions among beam particles, and orbital excursions, all lead to positrons being lost from the beam and striking the vacuum chamber. The following empirical formula, adapted from Swanson, et al. (SWA 85), can be used to estimate the bremsstrahlung dose at $1 \mathrm{~m}$ due to a positron interaction:

$$
\frac{H}{W}=1.67 \times 10^{-2} E_{0} 2^{-\left(\theta B / \theta_{1} / 2\right)}+(0.833) 10^{-\theta B / 21}+(0.025) 10^{-\theta B / 110},
$$

where $H$ is in rems, $W$ is in joules, $E_{o}$ is the positron energy in $M e V$, $\theta_{B}$ is the bremsstrahlung angle in degrees and $\theta_{1 / 2} \mathrm{E}_{\mathrm{o}}=100 \mathrm{MeV}$ deg. The first term on the right side of the expression accounts for the highly peaked forward component of the bremsstrahlung. Figure $I$ illustrates the geometry for the 
continuous-loss case assuming uniform interactions around the ring. For a positron striking the vacuum chamber at point $Q$, the bremstrahlung dose $(\mathrm{rem} / \mathrm{J})$ at $P$ will be expressed by

$$
\frac{\mathrm{H} \mathrm{e}^{-\mu_{B R E M^{x}}}}{W(Q P)^{2}} \text {, }
$$

in which $H / W$ is evaluated for the relevant angle $\theta_{B}$, which is the angle between the forward direction of the positron beam at $Q$ and the line segment QP. The contributions from each point, due to uniform interactions around the orbit circumference, were calculated for both the unshielded case and for 0.8 of concrete shielding. This is shown in Fig. 2. Assuming isotropic emission for both the GRN and HEN components, the contributions (mrem/J) to the point $P$ will be given by

$$
\frac{0.63 e^{-\mu_{G R N} x}}{(Q P)^{2}} \text { and } \frac{0.075 e^{-\mu_{H E N} x}}{(Q P)^{2}}
$$

These contributions are shown in Figs. 3 and 4, for both the unshielded and 0.8-m concrete shielding cases. When the distributions are integrated over all angles, the result is the cumulative contribution at the point $P$ due to a uniform loss around the ring. The integrated contributions for the $0.8-\mathrm{m}$ concrete shielding case are

$$
\begin{aligned}
& \mathrm{H}_{\mathrm{BREM}}=2.03 \times 10^{-2} \mathrm{mrem} \cdot \mathrm{deg} / \mathrm{J} \\
& \mathrm{H}_{\mathrm{GRN}}=1.96 \times 10^{-3} \mathrm{mrem} \cdot \mathrm{deg} / \mathrm{J} \\
& \mathrm{H}_{\mathrm{HEN}}=7.92 \times 10^{-3} \mathrm{mrem} \cdot \mathrm{deg} / \mathrm{J}
\end{aligned}
$$

Assuming $6.62 \times 10^{12} \mathrm{e}^{+}$at $7 \mathrm{GeV}$ gives a total stored energy of $7414.4 \mathrm{~J}$. For a uniform loss rate around the ring and a beam mean lifetime of $10 \mathrm{~h}$, the energy loss rate is $1.3 \mathrm{~J} / \mathrm{h} \cdot \mathrm{deg}$ and the resultant dose rates are

$$
\begin{array}{ll}
\dot{\mathrm{H}}_{\mathrm{BREM}}: & 2.64 \times 10^{-2} \mathrm{mrem} / \mathrm{h} \\
\dot{\mathrm{H}}_{\mathrm{GRN}}: & 2.55 \times 10^{-3} \mathrm{mrem} / \mathrm{h} \\
\dot{\mathrm{H}}_{\mathrm{HEN}} & : 1.03 \times 10^{-2} \mathrm{mrem} / \mathrm{h}
\end{array}
$$

The total dose rate is $3.93 \times 10^{-2} \mathrm{mrem} / \mathrm{h}$, which is within the guideline. According to Swanson (SWA 85), the results are good to within about a factor 
of 3. However, the simplifying assumption of uniform bean loss along the entire circumference of the ring generally does not prove out. Experience at Aladdin and NSLS (SWA 85, BNL 51584) indicates increased radiation levels in the vicinity of open ends of bending magnets, around the straight sections, at maximum dispersion points in quadrupole magnets, and bremsstrahlung jets at the ends of straight sections. Additional localized lead shielding for bremstrahlung and dense polyethylene for the high-energy neutron component may have to be provided at high-loss points in the system.

\subsection{Loss of Total Beam at a Single Point}

For the case of a total beam loss at a single point, both the transverse and radial components need to be evaluated. For the transverse component, we assume a distance of closest approach of $3 \mathrm{~m}$ and $0.8 \mathrm{~m}$ of concrete shielding in place. For a point loss of $7414.4 \mathrm{~J}$, the estimated doses are

\begin{tabular}{|c|c|c|}
\hline $\mathrm{H}_{\mathrm{BREM}}$ & : & 50 mrem \\
\hline${ }_{\text {HRN }}$ & : & 4.7 mrem \\
\hline $\mathrm{H}_{\mathrm{HEN}}$ & : & $12 \mathrm{mrem}$ \\
\hline
\end{tabular}

For the radial dose component, the closest distance is about $25.3 \mathrm{~m}$, of which $6 \mathrm{~m}$ would be concrete due to the slant penetration through the shielding wall. The increased distance to the dose point, as well as the increased shielding thickness, would offset the increased bremsstrahlung in the forward direction and result in negligible doses.

\subsection{Bremsstrahlung into a Photon Beam Line}

It is necessary to guard against an accidental positron beam loss during injection, which could result in high energy bremsstrahlung radiation being directed down a photon beam line. This could result in very high radiation levels in the experimental area. To prevent this, a lead shutter is inserted into the photon beam line before injection begins. All beam lines require lead shutters, $25-\mathrm{cm}$ thick in the beam direction and $10 \mathrm{~cm}$ transverse to the beam direction. The shutters should be located within the shield 
tunnel to adequately shield the neutrons produced by the electromagnetic shower in the lead.

On the assumption that $10 \%$ of the positron beam is lost, a resultant unshielded bremsstrahlung dose of $4.3 \times 10^{4}$ rem at $1 \mathrm{~m}$, due to stopping the positron beam, would be produced in the forward direction. If this were to occur just inside of the shield wall, the total dose at $1 \mathrm{~m}$ from the outside of the shield would be $5 \mathrm{mrem}$ due to the $25 \mathrm{~cm}$ lead shutter and $80 \mathrm{~cm}$ of concrete, and an assumed distance of $2.1 \mathrm{~m}$.

\subsection{Forward Bremsstrahlung Beam into Ratchet Wall}

Since a portion of the shield is in the form of a ratchet wheel, one must guard against forward bremsstrahlung striking the shield head on. The shielding design for these sections features an $0.8-m$ concrete wall except for a $2^{\prime} \times 2$ ' slot through the wall, centered around the axis of the photon beam line. The shielding in this slot consists of $25-\mathrm{cm}$ of lead followed by $55 \mathrm{~cm}$ of concrete. Assuming $10 \%$ of the positron beam is lost and the resulting bremstralung beam strikes this shield head on, and the distance of closest approach is $1.8 \mathrm{~m}$, the resultant total dose per occurrence would be about 18 mrem.

\subsection{Scattered Bremsstrahlung into a Beam Line}

In addition to the lead shutters in the photon beam lines, lead collars which surround the photon beam tube will need to be installed to insure that any scattered bremsstrahlung radiation is intercepted by $10 \mathrm{~cm}$ of lead shielding. These lead collars must be strategically placed around the beam pipe and be of sufficient length to block all optical paths except that between the positron orbit and the beam tube aperture.

\subsection{Dose Rates in Module Experimental Areas}

The dose rate in the module experimental areas was computed with the aid of Fig. 5 which shows the various dose contributes outside the ring at different distances, assuming uniform beam loss around the circumference. For the module areas, a nominal distance of $22.8 \mathrm{~m}$ was used for the distance of closest approach and a beam mean lifetime of $10 \mathrm{~h}$ was assumed. The energy 
loss rate for these conditions is $1.3 \mathrm{~J} / \mathrm{h} \cdot \mathrm{deg}$. Using the dose components from Fig. 5, the dose rates become

$$
\begin{aligned}
& \dot{\mathrm{H}}_{\text {BREM }}: 2.1 \mu \mathrm{rem} / \mathrm{h} \\
& \dot{\mathrm{H}}_{\text {GRN }}: 0.21 \mu \mathrm{rem} / \mathrm{h} \\
& \dot{\mathrm{H}}_{\mathrm{HEN}}: 0.77 \mu \mathrm{rem} / \mathrm{h}
\end{aligned}
$$

The total dose rate of $3.1 \mu \mathrm{rem} / \mathrm{h}$ is well within the guideline.

\subsection{Direct Radiation Dose Rate}

The direct radiation dose rate versus distance from the positron orbit is shown in Fig. 6 for the assumption of a $0.3 \mathrm{~A}$ positron beam of $7 \mathrm{GeV}$ and $0.8 \mathrm{~m}$ of concrete shielding. The circumference of the orbit is $1060 \mathrm{~m}$ and a $10 \mathrm{~h}$ mean lifetime for the beam was assumed.

\subsection{Dose to the Public}

Assuming a minimum distance of $220 \mathrm{~m}$ to the nearest site boundary, and a total operation time of $8000 \mathrm{~h}$ per year, the site boundary annual dose is found with the use of Fig. 6 to be 1.2 mrem due to direct radiation.

The skyshine contribution due to the high energy component was computed using the expression for a well-shielded accelerator (RIN 75):

$$
\phi(r) \sim \frac{a Q e^{-\frac{r}{\lambda}}}{4 \pi r^{2}}
$$

in which $a$ and $\lambda$ are constants, $\phi(r)$ is the fluence rate $\left(n / \mathrm{cm}^{2} \cdot s\right)$, $Q$ is the source strength in $\mathrm{n} / \mathrm{s}$, and $\mathrm{r}$ is the distance to the dose point, in $\mathrm{cm}$. Values of $a$ and $\lambda$ quoted for DESY measurements by Rindi and Thomas (RIN 75) were used. These values $\left(a=7, d=3.3 \times 10^{4} \mathrm{~cm}\right.$ ) give the largest fluence rate values for the DESY measurements. No other electron accelerator data was cited by Rindi and Thomas, but values of $\lambda$ given for proton machines varied from about $3-8.5 \times 10^{4} \mathrm{~cm}$.

Values of the source strength $Q$ were computed based upon the yield $\left(0.12 \mathrm{n} / \mathrm{e}\right.$ ) given by Bathow, et al. (BAT 67) for $6.3 \mathrm{GeV} \mathrm{e}^{-}$: 


$$
Q=.12\left(\frac{\mathrm{n}}{\mathrm{e}^{\dagger}}\right) \frac{.63\left(6.62 \times 10^{12} \mathrm{e}^{+}\right) \mathrm{e}^{-2}}{3.6 \times 10^{4} \mathrm{~s}}=1.88 \times 10^{6} \mathrm{n} / \mathrm{s}
$$

for an assumed $10 \mathrm{~h}$ mean lifetime. The source strength $Q$ was conservatively increased by a factor of 3 since the equation for the fluence rate is believed to be good to a factor of 3 . Using the factor

$$
3.2 \frac{\mathrm{n} / \mathrm{cm}^{2} \cdot \mathrm{s}}{\mathrm{mrem} / \mathrm{h}}
$$

to convert to dose equivalent rate, $\dot{H}$ :

$$
\dot{H}=\frac{9.82 \times 10^{5} e^{-\frac{r}{3.3 \times 10^{4}}}}{r^{2}}\left(\frac{\mathrm{mrem}}{\mathrm{h}}\right) .
$$

For $\mathrm{r}=220 \mathrm{~m}=2.2 \times 10^{4} \mathrm{~cm}$, the above gives a dose rate of $1.04 \mu \mathrm{rem} / \mathrm{h}$. Assuming $8000 \mathrm{~h}$ operation, gives an annual dose of about $8.3 \mathrm{mrem}$. The total projected annual dose at $220 \mathrm{~m}$ from the positron orbit (at the nearest site boundary) is on the order of $10 \mathrm{mrem} / \mathrm{y}$, which is also within the guidelines. Computations have also been made for the direct and skyshine contributions out to $5 \mathrm{~km}$. These results can be found in LS-84 (MOE 87 ). 


\section{REFERENCES}

DOE 81 U.S. Department of Energy requirements for radiation protection, DOE order 5480.1 Chg . 6, Chap. XI-3 (1981).

DOE 84 U.S. Department of Energy, Proposed Revision of DOE Order 5480.1A, "Radiation Standards for Protection of Public," memorandum dated Sept. 17, 1984. REF. P.E.-243 (1984).

FAS 84 A. Fasso, K. Goebel, M. Hoefert, G. Rau, H. Schonbacher, G. R. Stevenson, A. H. Sullivan, W. P. Swanson, and J.W.N. Tuyn, "Radiation Problems in the Design of the Large Electron-Positron Collider (LEP)," CERN 84-02, (5 March 1984).

BAT 67 G. Bathow, E. Freytag, and K. Tesch, "Measurements on $6.3 \mathrm{GeV}$ Electromagnetic Cascades and Cascade Produced Neutrons," NUC. PHYS ., B2 (1967), 669-689.

ALS 73 R.G. Alsmiller, Jr. and J. Barish, "Shielding Against the Neutrons Produced when 400-MeV Electrons are Incident on a Thick Copper Target," Particle Accelerators, 5, (1973), 155-159.

TES $79 \mathrm{~K}$. Tesch, "Data for Simple Estimates of Shielding Against Neutrons at Electron Accelerators," Particle Accelerators, 9, (1979), 201206.

DIN 77 H. Dinter and K. Tesch, Dose and Shielding Parameters of ElectronPhoton Stray Radiation from a High Energy Electron Beam," Nuc. Inst. Meth., 143, (1977), 349-355.

NEL 68 W. R. Nelson, "The Shielding of Muons Around High Energy Electron Accelerators: Theory and Measurement," Nuc. Inst. Meth., 66, (1968), 293-303.

BAT 70 G. Bathow, E. Freytag, M. Kobbeling, K. Tesch, and R. Ka jikawa, "Measurement of Longitudinal and Lateral Development of Electromagnetic Cascades in Lead, Copper, and Aluminum at 6.0 GeV," Nuc. Phys., B20, (1970), 592-602.

RIN 75 A. Rindi and R. H. Thomas, "Skyshine - A Paper Tiger?," Particle Accelerators, Vo1. 7 (1975), 23-39.

SWA 79 W. P. Swanson, Radiological Safety Aspects of the Operation of Electron Linear Accelerators," Technical Report Series No. 188, IAEA, Vienna, (1979), and references therein. 
SWA 85 W. P. Swanson, P. M. Deluca, R. A. Otte, and S. W. Schilthelm, "Aladdin Upgrade Design Study: Shielding," University of Wisconsin, 1985.

BNL 51584 K. Batchelor, Editor, National Synchrotron Light Source Safety Analysis Report, Brookhavaen National Laboratory, July 1982.

MOE 87 H. J. Moe, "Radiological Impacts from Operation of Argonne Synchrotron X-ray Source," ANL Report, Light Source Note LS-84 (March 1987). 
Fig.1. Geometry for Component Doses due to Continuous Loss around the Storage Ring

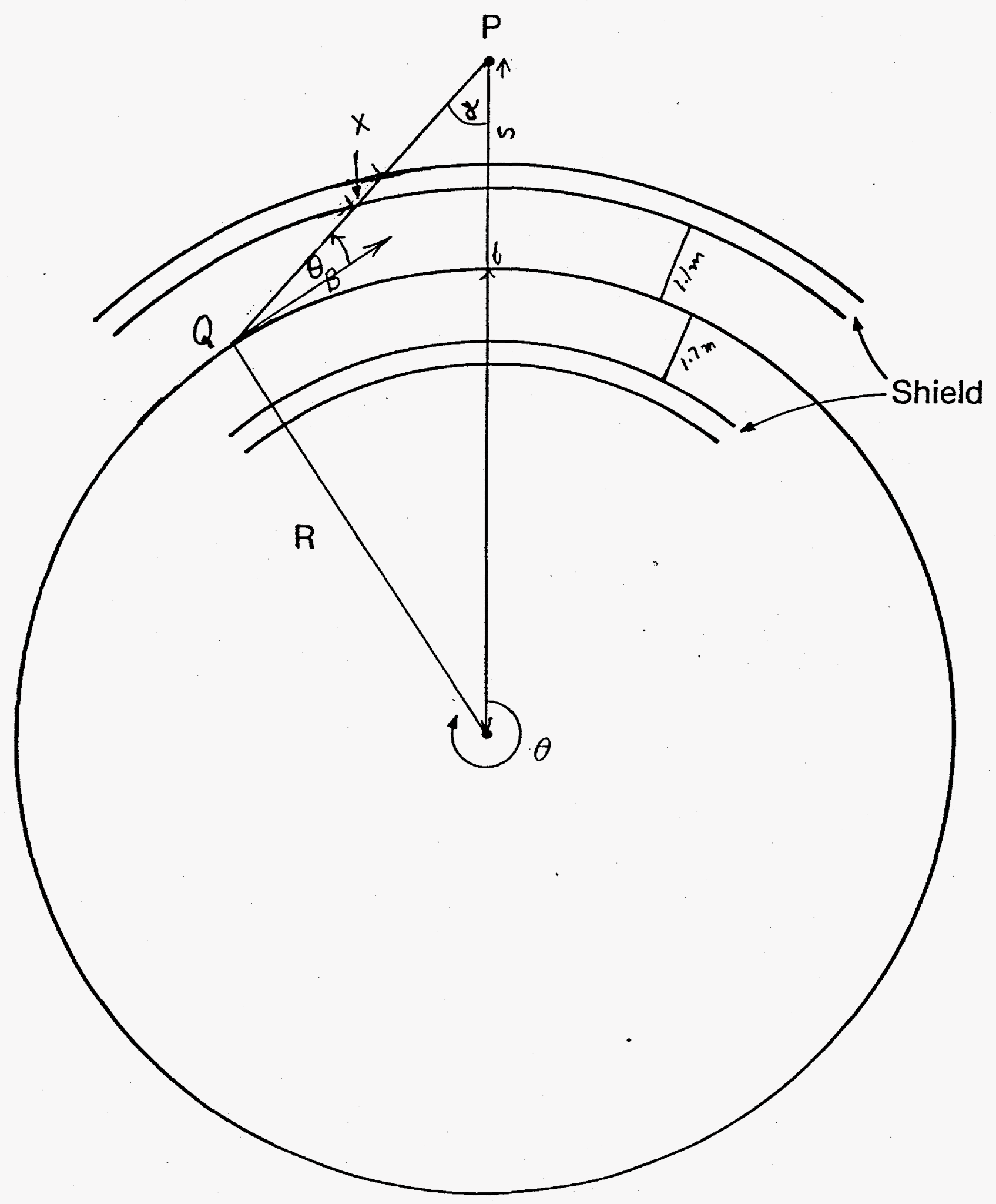




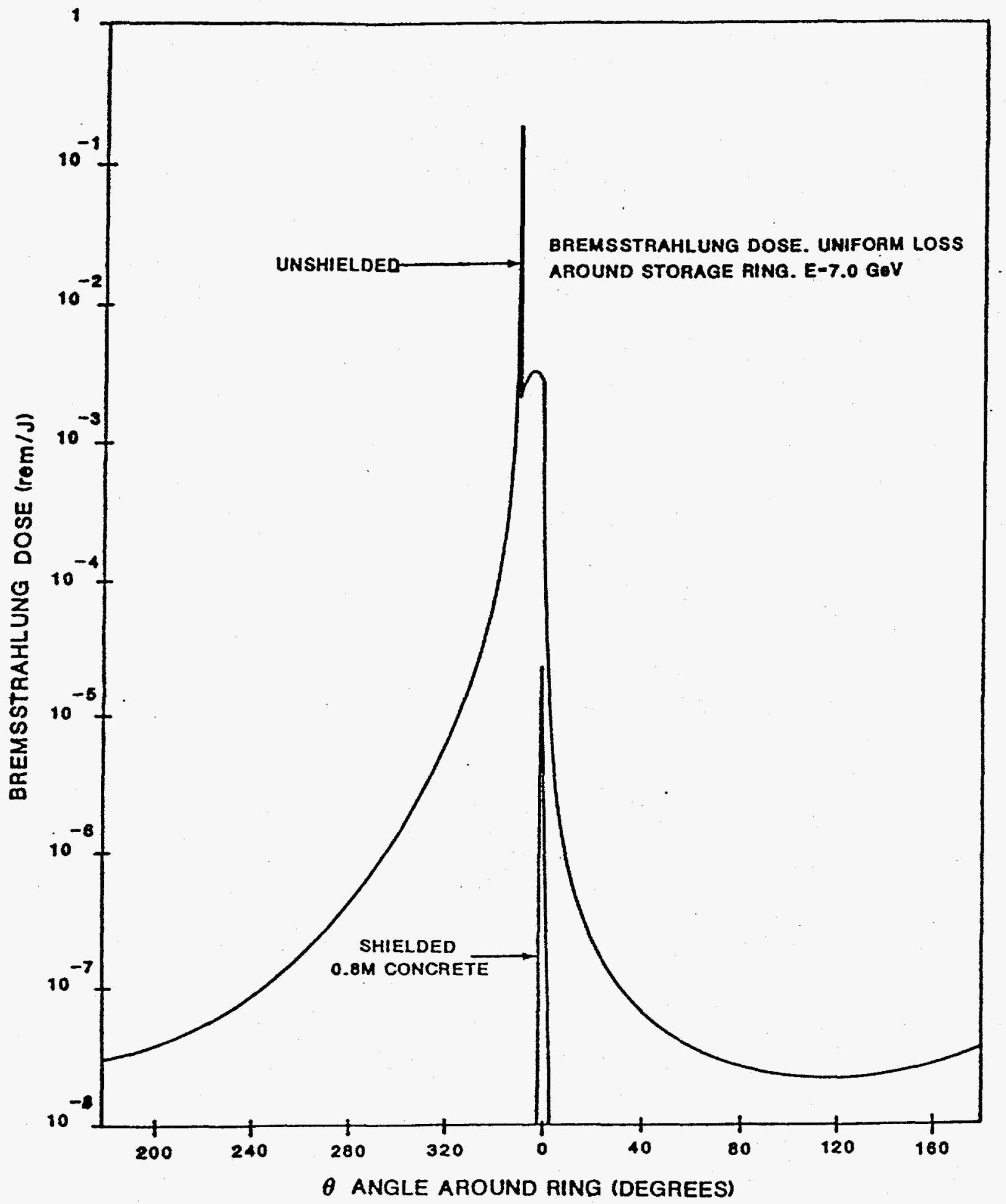

Figure 2. Bremsstrahiung Dose - Uniform Loss Around Storage Ring 


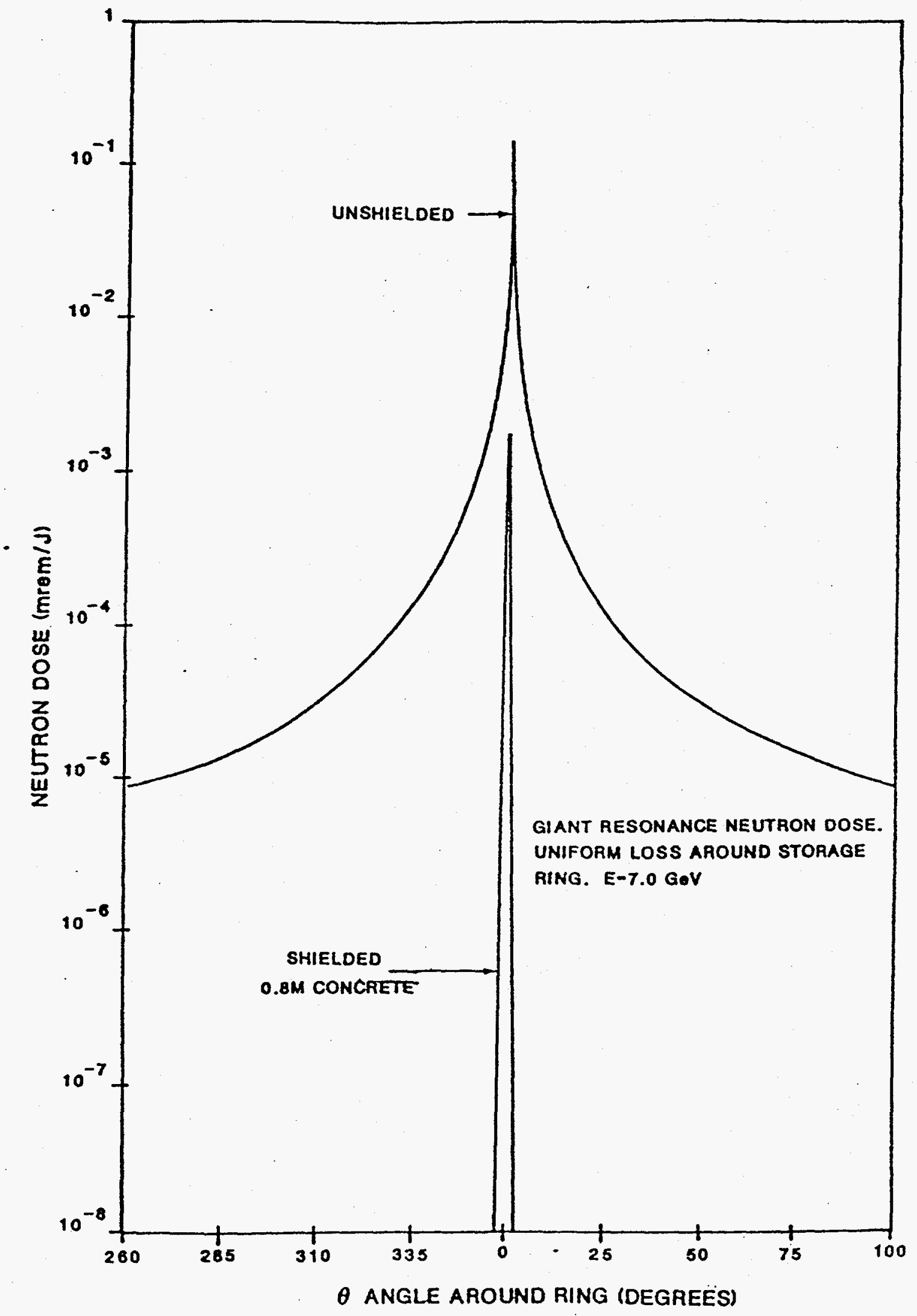

Fịgure 3. Gịant Resonance Neutron Dose-. Uniform Loss Around Storage Ring 


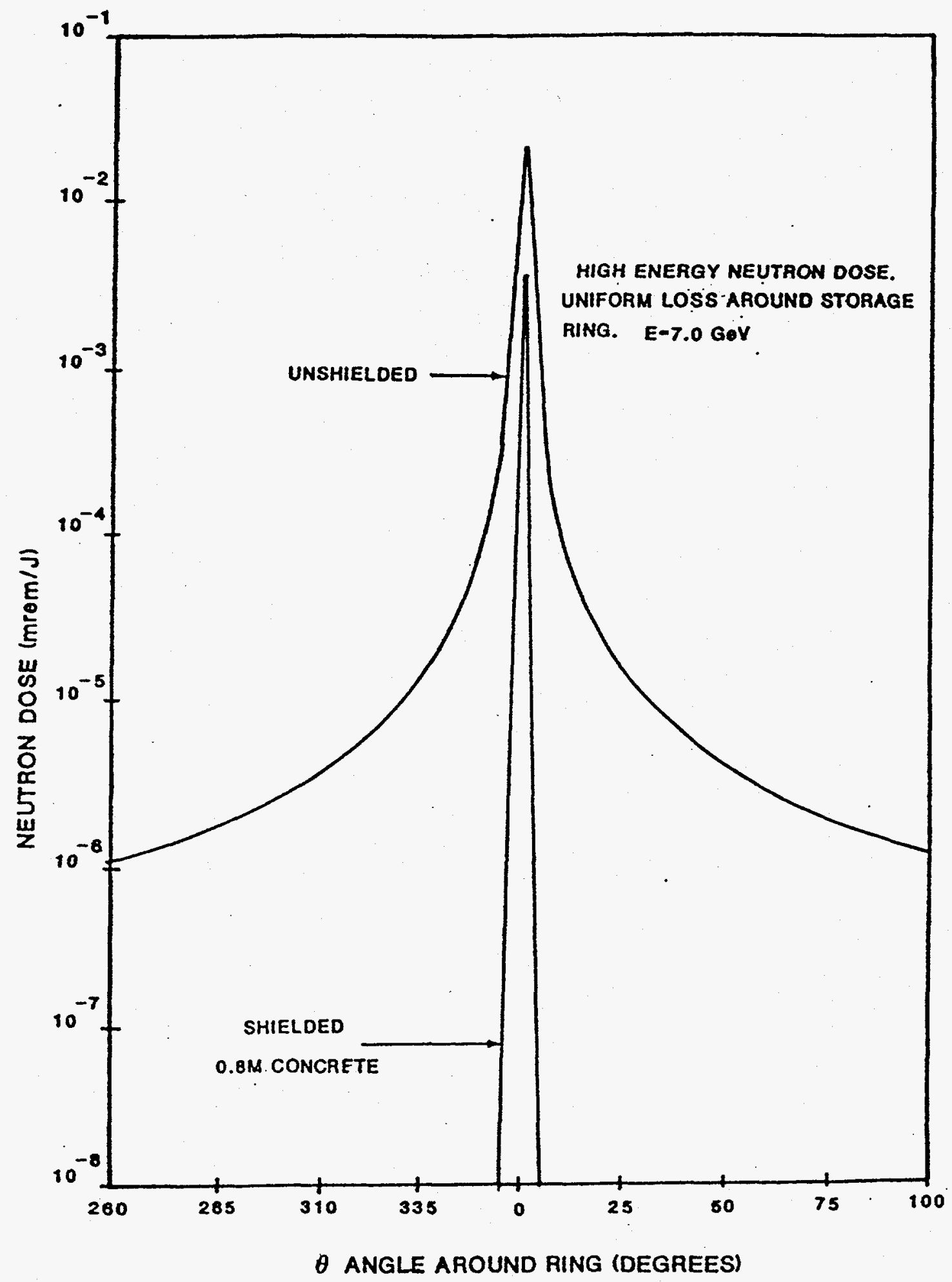

Figure 4- High Energy Neutron Dose Uniform Loss Around Storage Ring 


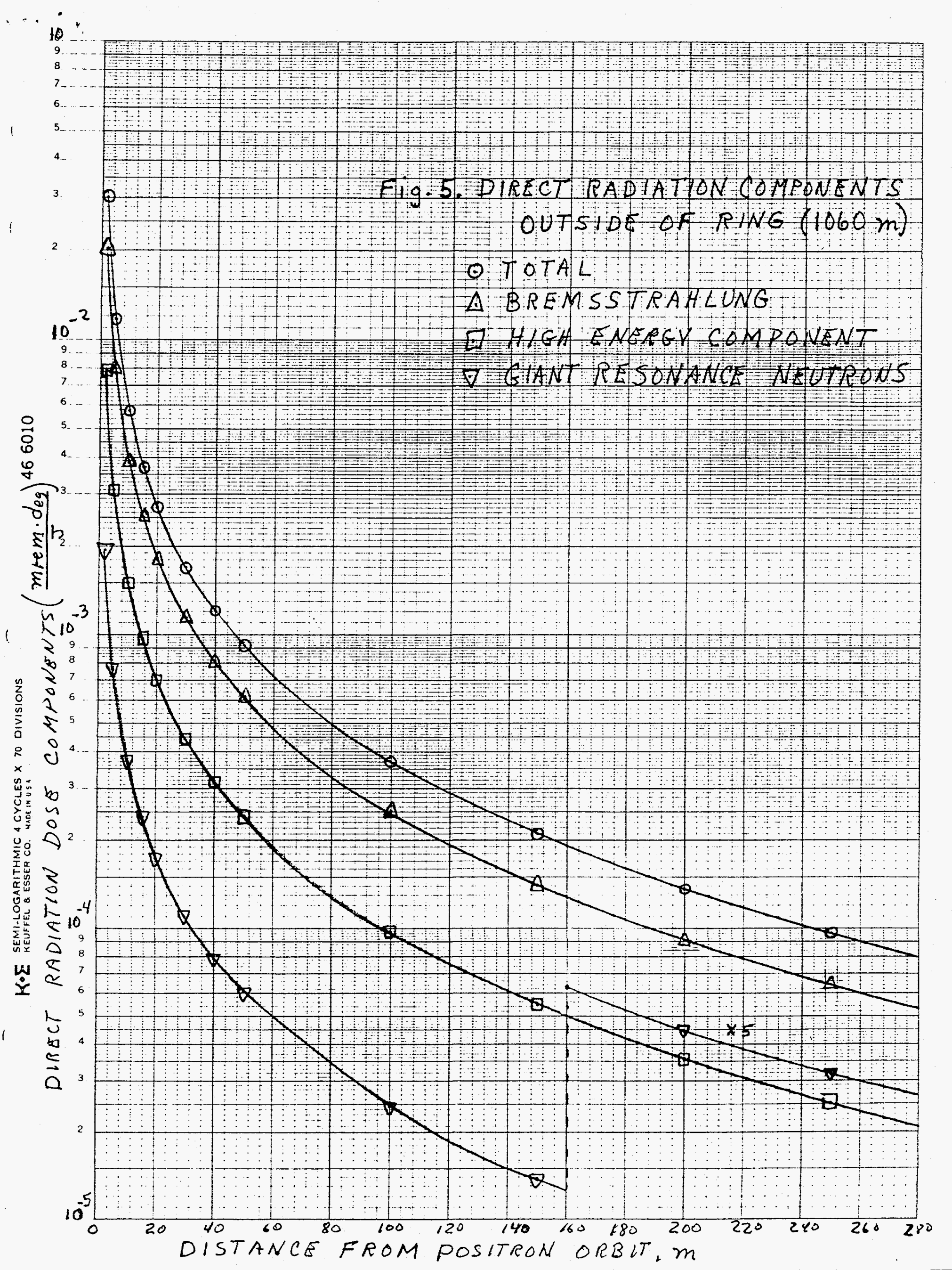




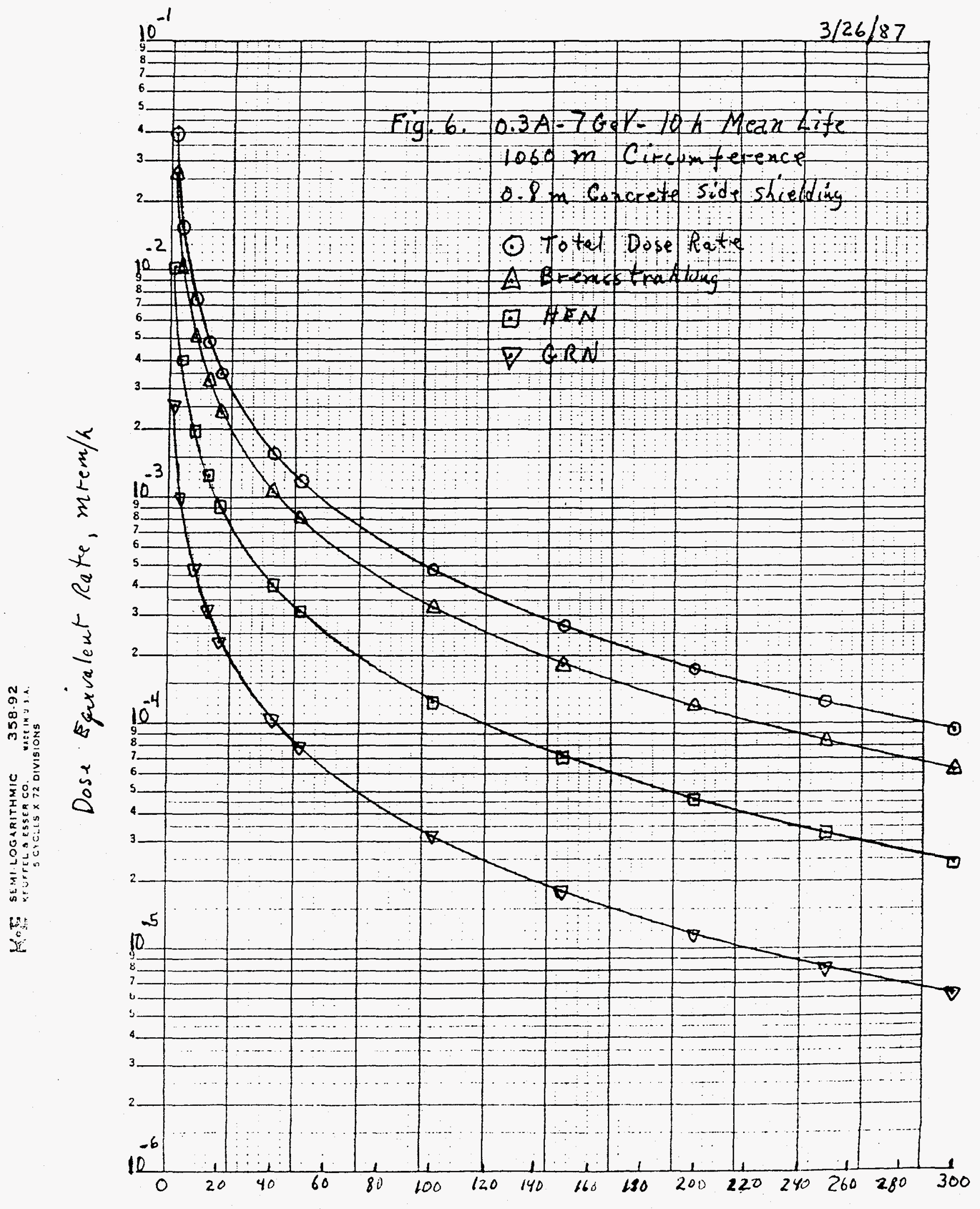

nictare from Positron Orbit, $m$ 